\title{
Mapping research in the field of special education on the island of Ireland since
}

2000

Joseph Travers, Rosie Savage, Cathal Butler, Margaret O Donnell

Joseph Travers, Rosie Savage and Margaret O Donnell

School of Inclusive and Special Education

Dublin City University Institute of Education

St Patrick’s Campus, Drumcondra

Dublin 9

Ireland

joe.travers@dcu.ie

35318842040

Cathal Butler

University of Bedfordshire

Dear Editor

This paper is based on a commissioned research project for the National Council for Special Education in Ireland. This paper is original and not under consideration or published elsewhere.

Joseph Travers 
Mapping research in the field of special education on the island of Ireland since 2000

\section{Abstract}

This article describes the process of building and findings from analysis of a database mapping research and policy in the field of special education on the island of Ireland from 2000-2013. The database contains 3, 178 references organised thematically and forms a source for researchers to access non published materials such as theses.

Analysis of the database reveals areas of research strength in terms of the quantity of activity and other areas with little activity. Recommendations are offered based on this analysis. 


\section{Mapping research in the field of special education on the island of Ireland since 2000}

\section{Introduction}

In educational research, a number of large national and international databases exist, which include research articles, chapters, books, and reports. These include international databases such as ERIC, and commercial databases such as EBSCO. There are also national databases such as the British Education Index, the Canadian Education Index, and the Australian Education Index. This paper describes the process and the findings emerging from creating an Irish-specific research database that aims to catalogue all relevant research and policy related material carried out in the field of special education since the year 2000 on the island.

\section{Special Education in the Republic of Ireland and in Northern Ireland}

The field of special education in the Republic of Ireland has changed enormously since 2000. Major influences such as international commitments to inclusive education (UNESCO, 1994), landmark court cases, and parental expectations, have caused changes in the education system. Policy formulation and implementation have supported an inclusive education agenda through the passing of landmark legislation (Government of Ireland,1998, 2004); the publication of key task force reports (department of education and science 2001a, 2001b); and issuing policy circulars to schools (e.g. Department of Education and Science, 2003, 2004, 2005, 2007).

The National Council for Special Education has been established on a statutory basis (Government of Ireland, 2004). Additional bodies supporting special and inclusive education include the National Educational Psychological Service (NEPS); the Special Education Support Service (SESS) and National Council for Curriculum and Assessment through the development of curricular guidelines (NCCA $2002,2007)$ for teachers of students with general learning disabilities. Major changes have also occurred in teacher regulation and in teacher education.

The National Council for Special Education which has a research and policy remit has funded key research and has published four policy advice papers since 2011. This advice covered the future role of special schools and classes, the education of deaf and hard of hearing children, the education of students with challenging behavioural and supporting students with special educational needs, including resource allocation (NCSE, 2011a, 2011b,2012, 2013). We have also had the introduction 4 of a national literacy and numeracy strategy, proposals for major overhaul of the Junior Cycle 
including the introduction of courses appropriate for students with more severe general learning disabilities, a forum on patronage of schools and proposals to change enrolment policies (Department of Education and Skills, 2011b, 2011c, 2012).

In Northern Ireland special education since 2000 has been marked by a period of review and reflection. This has included legislation, reviews of provision for pupils with statements and reports on special schools, transition, special education in initial teacher education, inclusion at preschool level, autism, dyslexia, speech and language provision, behaviour support units and the code of practice. Similar changes to the profile of students with special educational needs in mainstream and special schools have occurred in Northern Ireland as in the Republic. Following prolonged consultation and review the formal consultation document Every School a Good School: The Way Forward for Special Educational Needs and Inclusion set out proposals for improvements to the existing framework (Department of Education, 2009). This was followed by a Summary Report of Responses to the Consultation published in 2012 and a round of discussions with key stakeholders (Department of Education, 2012).

The proposals aim to standardise supports across the Education and Library boards and schools. It seeks to increase the statutory duty on Boards of Governors of ordinary schools to identify, assess and make appropriate provision for children with special educational needs in schools. A new statutory duty to ensure children with special educational needs have a personal learning plan with a greater emphasis on targets and outcomes is also proposed. For children with more complex needs a statutory coordinated support plan would be put in place with an annual review. Further legislative changes proposed include appropriate provision for preschool children with SEN.

\section{The Research Context}

As part of the Education for Persons with Special Educational Needs Act (2004), the National Council for Special Education was given a remit in relation to research in the field in the field of special education. A gap existed in terms of our knowledge of what research had been done, where, by whom and in what areas. The database that this article describes is part of a project funded by the National Council for Special Education. The aims of the project are firstly to provide a searchable research database for researchers, teachers, policy makers, parents and others conducting research or working in the field of special education. Secondly, it aims to provide for a more efficient use of 
research resources as it helps to highlight the evidence base on which to build. Thirdly, the inventory aims to aid the highlighting of gaps in the special education research knowledge base.

The function of the inventory and searchable database is not to assess the evidence found but to describe and categorise relevant research and policy-related activity in the area of special educational needs since 2000 in Ireland both north and south. Based on the premise that a wide range of research evidence can help inform the development of practice and policy in special education, a broad definition of research and policy-related material is used in the inventory. It includes doctoral and masters' theses, peer and non-peer reviewed journal articles, articles in professional journals, books, book chapters, reports and guidelines from voluntary, government and statutory agencies, legislation and circulars. Undergraduate dissertations, newspaper articles and unpublished conference papers were excluded. This has resulted in 3,178 database references from 2000 up to the end of 2013 conducted in two tranches, 2000-2009 and 2010-2013.

There have been few systematic attempts to catalogue Irish educational research. Murphy (1968) for example produced a list of education theses conducted in University College Cork from 1914 to 1967. Of the 43 theses four had a special education focus. The earliest dated from 1926 and was a study of the measurement of mental ability and school achievement by John Sullivan. The others date from the 1950s and 1960s and serve to illustrate progression in our understanding of and sensitivity to children's rights as equal citizens. The topics included a focus on "rehabilitation of the mentally handicapped"; "education of backward and subnormal children in Cork" and the "causes of reading backwardness in a group of mentally-retarded boys" (Murphy, 1968).

Alvarez (1981) created a list of empirical educational research conducted in the Republic of Ireland, including reports, books, and articles. This list spans the years from 1960 to 1980 . A subject index follows the list. One of the subjects identified is Special Education, with five references. An additional eight references are included under "disadvantaged populations." Applying the criteria used in the present study to the list would increase the overall total from 13 to 20 references. The index has 148 titles but this excluded theses which if included amounted to $65 \%$ of the original total of 400 considered studies. This provides some evidence of the very low base in terms of identified special education research in Ireland up to 1980.

Fontes (1983) analysed education theses in Irish universities from 1911 to 1982 in terms of their topics and distribution by university and degree. There were a total of 1,233 theses with nearly half ${ }^{6}$ 
of the theses completed from 1974 to 1982 . Nineteen different degrees were awarded.

Interestingly, the degree of Master of Education was awarded in Queen's University Belfast, nearly thirty years before the degree was introduced in the Republic of Ireland. Each thesis was categorised under 18 headings one of which was special education. In line with Alvarez (1981) special education has "roughly the same relatively low" frequency in the register of theses (Fontes, 1983, p.90).

The Educational Studies Association of Ireland (ESAI) website contains a register of theses from 1993 to 2000 (ESAl, 2015). It consists of 1,385 theses. For the purpose of this article an analysis of the entries by keywords in the titles related to the field of special education was done and is illustrated in Table 1: 
Table 1.

The level of research over this 17 year period in the field of special education was quite low.

Sheffield and Saunders (2002) present an analysis of the British Education Index which includes a discussion on the fortunes of the subject term special educational needs which illustrates the complexity of compiling and analysing such a database. In 1962 the term "Backwardness" had 45 counts and was ranked $18^{\text {th }}$ in the database. In 1997 the term "special educational needs" had 154 counts and was ranked $6^{\text {th }}$ in the database. By 2000 the usage frequency had halved and it had dropped to $15^{\text {th }}$ in rank position. However, scholarly outputs were becoming more specialised and narrower terms such as autism, behaviour-problems, blindness, cerebral palsy, conductive education, deafness, diagnostic assessment, Down's syndrome, dyscalculia, dysgraphia, dyslexia, enrichment, exceptional, gifted, hearing impairment, intervention, learning disabilities, mainstreaming, moderate learning difficulties, neurological impairments, severe learning disabilities and special educational needs statements were being used. In addition the broader terms inclusion and inclusive education would be relevant to the field. The authors comment that "as a concept moves from the fringes to a central position, it becomes more pervasive and the need to distinguish its constituents becomes more important. This process entails a moving and uncertain balance between changes in the research field of education and the flexibility of indexing policies and technologies" (Sheffield \& Saunders, 2002, p.179).

It can be seen from this that a study of the terms comprising a subject term is a project in its own right (Sheffield \&Saunders, 2002). It also highlights some of the difficulties with using databases for analysis which seek to capture too broad an area. Sheffield and Saunders $(2002$, p.180) suggest that "more reliable knowledge might only be available for accounts that have a narrower focus." In terms of the potential uses of data bases Sheffield and Saunders $(2002$, p.165) argue that "information services are easily overlooked as sources of narrative about change. In a simple way they might, over time, reflect changes (or stasis) in research focus and interest but they also indicate more profound cultural change." Holbrook, Findlay, and Mission analysed the Australian Education Index (AEI) to monitor the type of research that has occurred in the area. Hsu et al (2012) present an example of a study which uses data from a content analysis of selected journals to track trends in technology base learning. The present study reports on the construction of a database of special education publications and then uses data from it to track trends in research in the area since 2000. 


\section{Methodology}

The following steps were taken in relation to information gathering. First, the different sources for collecting references and the different types of reference were identified. Following this, a set of search and exclusion terms were selected and the sources were searched according to these. Finally, a list was drawn up indicating the types of information that we wished to collect for each reference.

A variety of sources of data were consulted in compiling the database. These included:

- Acts - These were located through a search of Acts on relevant Government websites in Northern Ireland \& the Republic of Ireland

- Articles: Major International databases ERIC, EBSCO, and google scholar were searched, with duplicates from multiple sources being removed. Irish journals which were not available in these databases were hand searched, or in the case of REACH, its' own database was searched.

- Books / Book Chapters : Google books, as well as ERIC, EBSCO were searched for relevant books. Searches were also conducted on the online catalogues of Irish Universities.

- Circulars - These were located through a search of circulars on relevant government websites in Northern Ireland \& the Republic of Ireland.

- Theses: Online library catalogues of all major universities and Institutes of Technology in Ireland for information on theses, and books. Relevant departments and institutions were also contacted via letter to ensure that information on all relevant theses was accessed.

- Reports: A list of relevant groups was drawn up for the Republic of Ireland and Northern Ireland. Letters were sent to these organisations, alongside searches of their websites to gain information about reports relevant to special education published by each organisation.

- Websites of all third level educational institutions on the island.

\section{Search Terms}

Table 1 below shows the range of search terms used when performing literature searches across a variety of sources. The terms used include variants on the term special educational needs, the categories of need that are used in the Republic of Ireland and Northern Ireland, and other relevant terminology such as Inclusion and Learning Support. Where the database searched was international (e.g. ERIC), an additional search term of Ireland was added, to ensure that only research relevant to the island was found.

\section{Table 2.}


The following inclusion and exclusion criteria were applied in compiling the database. First, the starting point of the project was the year 2000. Policy documents were interpreted as including Department of Education and Skills Circulars, Government Acts, and Judgements given the role that legal cases have had in the Irish special education context. Postgraduate theses at Master's and Doctoral level were also included but no undergraduate work.

When looking at research, a number of further exclusion criteria were further determined. First, research that was not primarily conducted on the island of Ireland was not included. Second, research where special education, or a special education relevant theme were not central were excluded.

\section{Data Collected for Each Reference}

For each reference collected and entered into the database, the following was collated. First, the basic publication details were gathered - author, year, title, and further publication details. Additional information in relation to the research was collected where possible - e.g. the type of research that was involved, the sample size, age range, educational setting, and country. There were also a number of references, mainly theses, where the researchers were not able to gather sufficient data in order to gather the relevant data, due to the lack of access to the thesis itself, or the abstract. Where applicable a category or categories of special educational needs based on the Irish classification system was assigned to an entry. For all entries a theme or themes were generated based on a process outlined below.

\section{Themes}

A number of databases such as ERIC and the BEI include multiple descriptors per reference. A decision was made to follow the same trend. The basis for deciding whether a theme was appropriate was through a content analysis of the title of the reference, the abstract where possible, the complete article/book/report/thesis where possible, and looking at descriptors and keywords that had been ascribed to references in other databases or in journals. Themes were deliberated on until consensus was reached on all. In some cases this involved merging similar themes or creating new ones to capture different aspects of the research area.

\section{Analysis of Entries}

In order to map trends in the database descriptive statistical analysis was completed in relation to

the number of entries in each category by year, the top journal entries, theses by type and institution, entries by category of special educational need and by themes. 


\section{Findings and discussion}

The results will cover a number of areas: the number and different types of references; trends year by year; the number of theses produced; the number of references per category of special educational need and the number of references per theme.

\section{Number and Type of Reference}

At the end of 2013 there were 3,188 entries in the database. From 2000 to 2009 there were 1, 693 with nearly a doubling of output in the following four years. The most common reference is articles in Irish and international journals, followed by theses and reports (Figure 1). Figure 2 shows the growth trend in terms of number of references produced per year. The fall in references in 2013 needs to be treated with extreme caution. An issue effecting the compilation of all databases that seek to be as up to date as possible is when to draw a cut-off point. In this case the gathering of data occurred in the first half of 2014. Many relevant references for 2013, particularly theses, had not been added to local databases at this stage. In addition some journals can be behind with publications. These contribute to the lower figure for 2013.

Figure 1.

Figure 2.

Research in the field of special education on the island since 2000 is represented in 265 national and international journals from a variety of disciplines, with the largest number of references coming from the Irish-based journals of REACH Journal of the Irish Association of Teachers in Special Education, Learn, Journal of the Irish Learning Support Association and the Frontline of Learning Disability. The recent inclusion of REACH in the EBSCO database is noteworthy. The expanding range of journals featuring Irish scholarship in the area is indicative of the mainstreaming of many special education concerns within a wider educational, social, economic and political context. 
Table 3.

Theses at Masters and Doctoral level are a key vehicle of particularly teacher research in special and inclusive education. Table outlines the types of postgraduate degree programmes contributing to research in special education. The Master of Education (M.Ed) is the most popular vehicle for such research, followed by Master in Arts (MA). In more recent years more specialised Masters in Special Educational Needs have developed. While at doctorate level most researchers have followed the $\mathrm{PhD}$ route there are a growing number of taught doctorates leading to research in special education.

Table 4.

Twenty eight institutions contributed to the thesis total of 987 . Of these institutions activity was most pronounced in St. Patrick's College, Drumcondra, a college of Dublin City University, Trinity College, Dublin, Mary Immaculate College, Limerick and University College Dublin which together accounted for $54 \%$ of the total number of theses.

\section{Categories of SEN}

Table 5 below shows the number of references in relation to the different categories of special educational need. It is striking that Autistic Spectrum Disorders are the most commonly referenced category of need. This is the case in both Northern Ireland and the Republic of Ireland. Autism Spectrum Disorder was only recognised as a distinct category of special educational needs in the Republic of Ireland in 1998. Since 2009 there has been a noted increase in references relating to ADHD and emotional behavioural disorder, autism and general learning disability/intellectual disability.

Interestingly, the area which garners most resources (such as allocation of special needs assistants and resource hours) in mainstream schools in the Republic of Ireland is that of emotional and behavioural difficulties (NSCE, 2009) and it has received relatively little research attention. The reasons for this are not clear and may include the lack of lobbying, fundraising and advocacy for these learners in the system.

Table 5. 


\section{Themes in the database}

Table 6 .

Analysis of entries led to the generation of 91 themes. Many entries cover two or more. Themes with over a hundred references reflect and help track many of the key research issues of the period. Understandably, given the legislative and socio-political context, there are 471 references to 'inclusion' across articles, books, theses and reports with a 100\% increase in references in the 20102013 period over the 2000-2009 period. Areas focused on within inclusion include attitudes, issues around social inclusion, teaching for inclusion, case studies of inclusion, teacher education and inclusion and research focusing on the inclusion of specific categories of special educational needs. There are also theoretical issues about the nature of inclusion, frameworks of inclusion and how it can be implemented.

The needs of parents, caregivers and siblings features very strongly as a theme as does services in terms of access and quality of provision. The period is question has also been marked by distinct policy initiatives largely around supporting the inclusion agenda and this is also reflected in the database alongside and emphasis on educational provision. The particular challenges associated with the post primary stage of education around transition and access, participation and benefit is receiving research attention. Educational interventions in literary and communication feature strongly as does the area of assessment. The interaction of special needs and mental health and care issues reflects the growing awareness of the challenges of meeting the needs of all citizens in these areas. There has been a five-fold increase in references in the mental health area over the two periods of data collection.

At the other end of the database in terms of themes, are those areas with little research activity. In contrast to England, the Republic of Ireland does not have the designated position of a Special Educational Needs Coordinator (five references) and there is little research in this area. Other areas with a low research emphasis include ethnic minorities and special educational needs (four) and the interaction of special education and Irish language issues (14). The issue of dual enrolment/placement has also received relatively little research attention (1). Given current policy considerations in both jurisdictions it is noteworthy that there is little research on funding models and resource allocation.

\section{Recommendations}

The number of entries in the database of 3,188 represents just short of a $100 \%$ increase in entries in the period 2010-2013 over the period 2000-2009. This is a welcome development and shows the 
continued interest, commitment and endeavour in the field of special and inclusive education. The increased output is noticeable particularly across theses, articles and reports. The development of Masters' programmes in special education across many institutions is a major stimulus for research. This has been added to by the development of professional doctoral programmes in education and psychology and structured PhDs in many institutions. This has resulted in nearly a third of the database consisting of theses in the field. Issues highlighted by this work include the nature of this research which tends to be small scale and single author. While such work can be of varying quality there are challenges in terms of its dissemination and possible impact. To extract maximum benefit from this wealth of research activity some institutions publish full versions of theses online, others publish abstracts. Other options include institutions selecting the best of this research over a period of time and publishing shortened versions as an edited book or encouraging students to co-author with supervisors. Inter-library loans could be facilitated by electronic access to the theses on request if unlimited access is not possible. Edited books of teacher research and co- authored journal articles based on master's and doctoral theses feature more prominently in the database since 2009.

The increase in the number of reports in the database has been helped by the activities of the National Council for Special Education which has a strategic remit in relation to research in field and that research influencing policy advice. There may be a role for the Council in encouraging more cross disciplinary research in addressing some of the gaps identified in the database in the future.

The contribution of Irish-based special educational / disability journals such as REACH Journal of Special Needs Education in Ireland, Learn Journal of the Irish Learning Support Association and the Frontline of Learning Disability as vehicles for the dissemination of research findings and policy analysis while also giving a voice to practitioners and parents in the field is significant in the database. The inclusion of REACH in the EBSCO research database is a very significant development in the dissemination of Irish research in the field of special and inclusive education to a world-wide audience. Providing full-text online access to the other Irish journals would greatly aid dissemination.

There are a number of policy areas in both jurisdictions which when matched with the available research in the database suggest a paucity of local evidence to draw on. These include, inter alia, teacher education for special and inclusive education; empirically validated pedagogy; curriculum provision at post primary level, interagency and collaborative work; leadership for inclusion; digital learning and special and inclusive education; interagency collaboration; the needs of students with 
special educational needs in Gaelscoileanna and Gaeltacht areas; multi-disciplinary work; quality assurance and funding, allocation and deployment of resource models.

In summary, the database provides a useful resource for accessing material and analysing trends and gaps in research. To remain relevant it requires regular updating. The practice of some organisations not to date much of their online publications should also be discontinued. 


\section{References}

Alvarez, B. (1981). Educational research in Ireland: A bibliography of empirical work 1960-1980. The Irish Journal of Education, xv, (1), 41-52.

Alvarez, B. (1984). A review of educational research in Ireland, 1960-1980. The Irish Journal of Education, xviii (1), 23-48.

Department of Education and Skills. (2011a). The special needs assistant scheme: A value for money review of expenditure on the special needs assistant scheme 2007/8 - 2010. Dublin: Author.

Department of Education and Skills. (2011b). Literacy and numeracy for learning and life: The national strategy to improve literacy and numeracy among children and young people 20112020. Dublin: Author.

Department of Education and Skills. (2011c). Discussion paper on a regulatory framework for school enrolment. Dublin: Author.

Department of Education and Skills. (2012). A framework for junior cycle. Dublin: Author.

Department of Education. (2009). Every school a good school: The way forward for special educational needs and inclusion. Belfast: Department of Education, Northern Ireland.

Department of Education. (2012). Summary report of responses to the consultation on every school a good school - the way forward for special educational needs and inclusion and the associated equality impact assessment. Belfast: Department of Education, Northern Ireland.

Department of Education. (2013). Disability Action Plan 2013-2015. Belfast: Department of Education, Northern Ireland.

Douglas, G., Travers, J., McLinden, M., Roberstson, C., Smith, E., Macnab, N., Powers, S. Guldberg, K., McGough, A., O'Donnell, M., \& Lacey, P. (2012).Measuring educational engagement, progress and outcomes for children with special educational needs: A review (NCSE Research Report No.11). Trim: National Council for Special Education. Government of Ireland. (2004).

Educational Studies Association of Ireland (ESAI). (2015). Index of Education theses http://www.esai.ie/resources/cumulativeindexofeducationtheses

Fontes, P.J. (1983). Theses on educational topics in universities in Ireland their distribution by university, topic and degree. The Irish Journal of Education, xvii (2), 80-104.

Hsu, Y.-C., Ho, H. N. J., Tsai, C.-C., Hwang, G.-J., Chu, H.-C., Wang, C.-Y., \& Chen, N.-S. (2012). Research Trends in Technology-based Learning from 2000 to 2009: A content Analysis of Publications in Selected Journals. Educational Technology \& Society, 15 (2), 345-370.

Murphy, M. W. (1968). A list of theses on educational topics completed at university college Cork. The Irish Journal of Education, ii (2), 136-138. 
National Council for Special Education. (2011a). The future role of special schools and classes in Ireland. Trim: Author.

National Council for Special Education. (2011b). The education of deaf and hard of hearing children in Ireland. Trim: Author.

National Council for Special Education. (2012). The education of students with challenging behaviour arising from severe emotional disturbance/behavioural disorders. Trim: Author.

National Council for Special Education. (NCSE). (2013). Supporting students with special educational needs in schools. Trim: Author.

Sheffield, P. \& Saundesr, S. (2002). Using the British Education Index to Survey the Field of Educational Studies, British Journal of Educational Studies. 50 (1), 165-183.

Travers, J., Butler, C., \& O'Donnell, M. (2011a). An inventory of research and policy related publications in the field of special education on the island of Ireland since 2000 (NCSE research reports No: 8). Trim: National Council for Special Education.

Travers, J., Butler, C., \& O'Donnell, M. (2011b). An inventory of research and policy related publications in the field of special education on the island of Ireland since 2000, Supplementary report A: Alphabetical list. Trim: National Council for Special Education.

Travers, J., Butler, C., \& O'Donnell, M. (2011c). An inventory of research and policy related publications in the field of special education on the island of Ireland since 2000, Supplementary report B: Themes and categories of special educational needs. Trim: National Council for Special Education.

Travers, J., \& Savage, R. (2014). An inventory of research and policy related publications in the field of special education on the island of Ireland since 2000: Report on updating of database from 2009-2013: Supplementary report: List of titles in database. Trim: National Council for Special Education. 